\title{
Assessment of modified Rodnan skin score and esophageal manometry in systemic sclerosis: a study correlating severity of skin and esophageal involvement by objective measures
}

\author{
Tasleem Arif ${ }^{1}$, Mohammad Adil ${ }^{2}$, Jaswinder Singh Sodhi ${ }^{3}$, Iffat Hassan ${ }^{1}$
}

\begin{abstract}
Introduction: Systemic sclerosis (SSc) is a multisystem connective tissue disease characterized by immune-mediated activation of tissue fibroblasts and consequent fibrosis, vascular abnormalities, and inflammation. The skin and esophagus are the two most frequently involved organs in this disease. Data regarding the correlation between the severity of skin and esophageal involvement in SSc by objective measures are negligible so far.

Methods: Thirty-one patients with SSc were subjected to esophageal manometry. A correlation between modified Rodnan skin score (MRSS) and esophageal manometric parameters of lower esophageal sphincter pressure (LESP), percentage relaxation of the lower sphincter, amplitude, and duration of the peristaltic waves was established.

Results: The mean MRSS was found to be $16.9 \pm 8.7$. There was no statistical correlation between MRSS and LESP $(p=0.496)$, percentage relaxation $(p=0.070)$, amplitude $(p=0.531)$, and duration $(p=0.459)$ of the contractions. No difference between these manometric parameters was found if the patients were divided into limited and diffuse subsets.

Conclusions: There exists no correlation between the severity of skin involvement measured by MRSS and manometric abnormalities in SSc. All patients with SSc should undergo esophageal manometry irrespective of the extent of skin involvement.
\end{abstract}

Keywords: esophageal manometry, modified Rodnan skin score, systemic sclerosis

Received: 2 March 2018 | Returned for modification: 24 July 2018 | Accepted: 17 October 2018

\section{Introduction}

Systemic sclerosis (SSc) is a multisystem, autoimmune, connective tissue disease characterized by fibrosis, vascular abnormalities, and resultant inflammation (1). The disease leads to excessive deposition of collagen and resultant tissue fibrosis due to immune-mediated activation of fibroblasts in the skin and various internal organs (2). Cutaneous involvement is the most striking feature of the disease. It has been divided into limited cutaneous $\mathrm{SSc}$ (when the skin involvement is limited to the distal extremities and face) and diffuse cutaneous SSc (when there is more proximal skin involvement as well) (3). Involvement of the gastrointestinal tract is very common and is seen in around 75 to $90 \%$ of cases (4).

The esophagus is the most frequently involved part of the gastrointestinal tract in SSc, and esophageal abnormalities have been noted in more than three-fourths of all patients (5). Atrophy of esophageal smooth muscle and its replacement by fibrous tissue leads to muscular dysmotility, most prominent in the distal third of the esophagus (6). Esophageal manometry is believed to be the best tool in the study of esophageal motility (7). SSc is characterized by diminished peristalsis in the distal esophagus with loss of tone of the lower esophageal sphincter (LES) (8). This manifests clinically as gastroesophageal reflux disease and dysphagia. Complications such as esophageal stricture, Barrett's esophagus, and adenocarcinoma of the esophagus are more common in these patients compared to the general population (9).

The aim of this study was to evaluate the correlation between the severity of skin involvement with the severity of esophageal dysfunction, measured objectively by modified Rodnan skin score (MRSS) and esophageal manometry, respectively. To the best of our knowledge, this is the first such attempt to correlate the severity of these two systems using objective tools.

\section{Methods}

This prospective observational study was carried out at the Postgraduate Department of Dermatology, Sexually Transmitted Diseases, and Leprosy at Shri Maharaja Hari Singh (SMHS) Hospital of the Government Medical College (GMC), Srinagar and Department of Gastroenterology, Sheri-Kashmir Institute of Medical Sciences (SKIMS), Srinagar, India between November 2011 and March 2014. Ethical clearance was obtained from the Institutional Ethics Committee, SKIMS, and Ethical Committee of the Government Medical College, Srinagar. All new patients and patients already diagnosed with SSc attending the dermatology outpatient department of SMHS hospital were selected for the study. The American Rheumatology Association (ARA) Criteria were used to diagnose SSc (10).

The inclusion criteria were (a) patients of both sexes and (b) age more than 18 years. The exclusion criteria were (a) current pregnancy or pregnancy in the last 6 months, (b) patients that were on or had taken antifibrotic or immunosuppressant drugs, and (c) presence of other connective tissue diseases, mixed connective tissue disease, or diabetes mellitus.

Informed consent was given by all patients for inclusion in the study, including collection and recording and publishing of personal details and clinical photographs. Data recorded for the study consisted of age, sex, age of onset of disease, and duration of disease. The type of disease (limited or diffuse cutaneous SSc) was assessed using the Le Roy classification (11). Skin involvement was evaluated using the MRSS. Skin thickening was assessed by 
palpation of the skin in 17 areas of the body (fingers, hands, forearms, arms, feet, legs and thighs, face, chest, and abdomen) using a $0-3$ scale, where $0=$ normal, $1=$ mild thickness, $2=$ moderate thickness, and $3=$ severe thickness. Total skin score can range from o (no thickening) to 51 (severe thickening in all 17 areas). MRSS was calculated on two occasions-at the time of initial examination and at 12 weeks-and the mean value was calculated for the study. The patients were subjected to esophageal manometry. For manometry, overnight fasting was advised. The patients were instructed to avoid all drugs that affect gastrointestinal motility, especially anticholinergics, sedatives, antihypertensives, and anti-angina drugs for at least 1 week prior to the procedure. The patient was placed in a supine position and all tight clothing and jewelry worn around the neck was removed. The manometric instrument used had a special multilumen 16-channel catheter system (RedTech, Inc., Los Angeles, CA, USA). External pressure transducers were connected to the catheter, which were perfused with distilled water at a continuous rate of $0.5 \mathrm{ml} / \mathrm{min}$ by a lowcompliance pneumohydraulic capillary infusion system. Topical xylocaine jelly was applied to achieve anesthesia of the nasal mucosa and the catheter assembly was passed through it until the reading orifices reached the stomach. The station pull-through of the LES was performed at $1 \mathrm{~cm}$ intervals. Recording of lower esophageal sphincter pressure (LESP) was done at end expiration with mean gastric pressure as the baseline. Ten wet swallows of $10 \mathrm{ml}$ water each were administered, each swallow separated by a period of 30 seconds. The amplitude of the pressure wave was measured as the distance from the mean intra-esophageal baseline pressure to the peak of the wave. The LES relaxation pressure was measured as the residual pressure expressed as the percentage of the basal pressure. The duration of the pressure waves was assessed in seconds. Esophageal manometric reference values were taken according to Benjamin et al. (12).

The data collected were tabulated and analyzed with the help of Statistical Package for Social Sciences (SPSS) version 16.o. The mean, standard deviations, and percentages were calculated, and the Pearson correlation coefficient was calculated to look for possible correlations. A value of $p<0.05$ was considered statistically significant.

\section{Results}

Thirty-one patients were enrolled in the study. Their clinical and epidemiological features are shown in Table 1.

The mean MRSS for the patients was 16.9 with a standard deviation of 8.7 (Table 2). The various esophageal manometric findings of the patients are summarized in Table 3. The correlation between the MRSS and LESP was found to be slightly negative $(r$ $=-0.127$ ) with no statistical significance between the two (Fig. 1a;

Table 3 | Esophageal manometric findings of the patients.

\begin{tabular}{|c|c|c|c|c|}
\hline Manometric parameters & Mean (all patients) & Mean (limited SSc) & Mean (diffuse SSc) & $p$ value \\
\hline LESP & $21.6 \pm 12.6 \mathrm{mmHg}$ & $22.9 \pm 12.6 \mathrm{mmHg}$ & $18.8 \pm 12.8 \mathrm{mmHg}$ & 0.406 \\
\hline Relaxation \% & $73.2 \pm 17.4$ & $75.9 \pm 13.8$ & $67.7 \pm 23.2$ & 0.226 \\
\hline Amplitude & $17.3 \pm 24.4 \mathrm{mmHg}$ & $19.9 \pm 28.3 \mathrm{mmHg}$ & $11.9 \pm 12.4 \mathrm{mmHg}$ & 0.402 \\
\hline Duration & $5.5 \pm 5.8$ seconds & $5.4 \pm 5.6$ seconds & $5.6 \pm 6.4$ seconds & 0.930 \\
\hline
\end{tabular}

Duration
$\mathrm{LESP}=$ lower esophageal sphincter pressure, $\mathrm{SSC}=$ systemic sclerosis.

Table 4 | Correlation of modified Rodnan skin score and esophageal manometric parameters.

\begin{tabular}{|c|c|c|c|c|c|c|}
\hline \multirow{2}{*}{ Parameter } & \multicolumn{2}{|c|}{ All patients } & \multicolumn{2}{|c|}{ Limited SSc } & \multicolumn{2}{|c|}{ Diffuse SSc } \\
\hline & $r$ & $p$ value & $r$ & $p$ value & $r$ & $p$ value \\
\hline LESP & -0.127 & 0.496 & -0.050 & 0.823 & -0.038 & 0.917 \\
\hline Relaxation \% & -0.331 & 0.070 & -0.108 & 0.144 & -0.172 & 0.408 \\
\hline Amplitude & -0.117 & 0.531 & 0.014 & 0.951 & -0.295 & 0.087 \\
\hline Duration & -0.138 & 0.459 & -0.042 & 0.856 & -0.465 & 0.176 \\
\hline
\end{tabular}

$\mathrm{LESP}=$ lower esophageal sphincter pressure, $r=$ correlation coefficient, $\mathrm{SSc}=$ systemic sclerosis.

$p=0.496)$. There was a negative correlation between LES relaxation and MRSS ( $r=-0.331$ ), and this was not significant statistically (Fig. 1b; $p=0.070$ ). The correlation between the amplitude of the contractions and MRSS was found to be slightly negative (Fig. 1C; $r=-0.117)$ and non-significant $(p=0.531)$. On correlating the duration of contractions with MRSS (Fig. 1d), a negative correlation ( $r=$ -0.138 ) was found, which was not significant ( $p=0.459$; Table 4). The manometric parameters between limited and diffuse SSc were found to be statistically insignificant.

\section{Discussion}

SSc is an autoimmune disease with a female predisposition, which was also observed in our study because less than $10 \%$ of our patients were males $(13,14)$. The mean age of our patients at the time of presentation was 44.7 years. The average age of onset of disease was 36.1 years, and the patients presented to us after a mean duration of 8.6 years of developing noticeable changes of disease onset. Several studies have shown that SSc has an onset around the fourth decade of life, which is very near to our mean age of onset of disease $(15,16)$. Usually the mean time between onset of symptoms such as Raynaud's phenomenon or skin thickening and presentation is around half of the time seen in our study $(16,17)$. However, Sharma et al. also found a similar duration of presentation of patients and hypothesized that patients with SSc presenting to a dermatology clinic have a comparatively less symptomatic form of disease compared to those that present to rheumatology clinics (18). Around two-thirds of our patients had limited SSc, whereas the remaining third had a diffuse form of the disease. Other studies also point to the fact that the limited form of the disease is more common than the diffuse type, but the proportion of limited SSc varies considerably $(19,20)$. The mean MRSS score was calculated as 16.9 in our study. Patients with limited SSc had a mean score of 13.48 , whereas it was 24.1 for diffuse

Table 1 | Characteristics of the patients in the study.

\begin{tabular}{lc}
\hline Characteristic & Quantity \\
\hline Total number of patients & 31 \\
Males & $3(9.7 \%)$ \\
Females & $28(90.3 \%)$ \\
Mean age & $44.7 \pm 13.4$ years \\
Mean age of onset & $36.1 \pm 12.6$ years \\
Mean duration of disease & $8.6 \pm 6.1$ years \\
Limited systemic sclerosis & $21(67.7 \%)$ \\
Diffuse systemic sclerosis & $10(32.3 \%)$ \\
\hline
\end{tabular}

Table 2 | Mean modified Rodnan skin score of the patients.

\begin{tabular}{lccc}
\hline Patient group & Number & Mean MRSS & Standard deviation \\
\hline All patients & 31 & 16.9 & 8.7 \\
Limited SSc & 21 & 13.5 & 7.3 \\
Diffuse SSc & 10 & 24.1 & 6.9
\end{tabular}

MRSS = modified Rodnan skin score, SSc $=$ systemic sclerosis. 


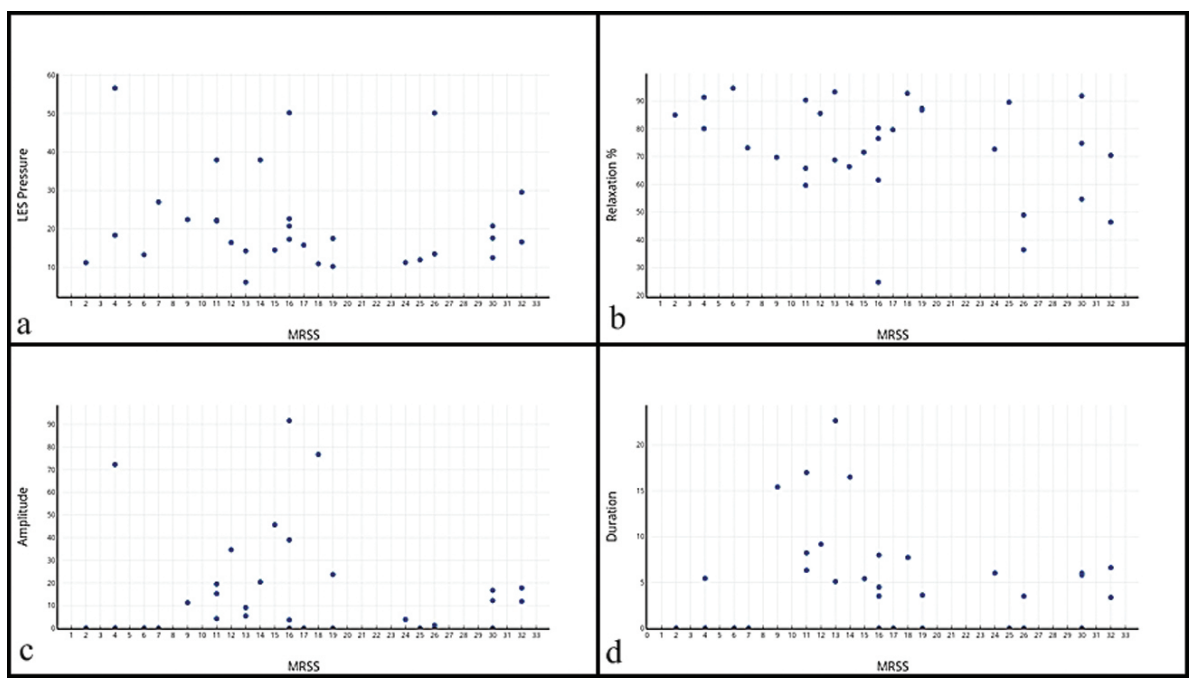

Figure 1 | Diagram showing correlation between modified Rodnan skin score (MRSS) and the four esophageal manometric parameters. There exists no significant statistical correlation between the MRSS and a) lower esophageal sphincter pressure (LESP), b) relaxation \%, c) amplitude of contractions, and d) duration of contractions.

SSc patients. Other studies have also shown the MRSS to be in the same range $(21,22)$.

Involvement of the esophagus can be seen in more than $70 \%$ of cases of SSc (6). The distal third of the esophagus is the most often and most severely involved area (23). Various causes for esophageal dysfunction have been proposed, such as vascular injury leading to ischemia, degeneration of the nerves, collagen deposition leading to fibrosis, and atrophy (24). A retrospective case control study on autopsy specimens showed that ischemic and inflammatory processes are not important in the pathogenesis of SSc. Rather, atrophy of the circular musculature of the esophagus is characteristic and may be responsible for the neural dysfunction of the esophagus, leading to dysmotility (25). The presence of involvement of the esophagus does not correlate with the presence of disease symptoms, and a large proportion of patients with documented abnormalities in the esophagus are asymptomatic (26). Manometry is considered the earliest and best detection modality of esophageal involvement in SSc (27). The common abnormalities seen with manometry include a lower median wave amplitude followed by LESP, and lower duration of contraction and percentage relaxation (28). Complete aperistalsis was observed in one-third of our patients. Aperistalsis is an important finding in $\mathrm{SSc}$ and is responsible for the gastro-esophageal reflux disease seen in such patients (29).

There have been few studies to evaluate the relation between the severity of SSc and the esophageal abnormalities seen with manometry. The matter has been complicated by conflicting reports of more severe esophageal involvement in one of the two subsets of SSc. Studies supporting more severe esophageal involvement in diffuse SSc argue that this subtype has a greater severity of internal organ dysfunction and consequently more severely involves the esophagus. Proponents of the theory that the limited cutaneous subset has more severe esophageal dysmotility argue their point on the basis that this type is associated with CREST syndrome $(30,31)$.

To date, there has been only one study by Kimmel et al. correlating the esophageal abnormalities assessed by high-resolution manometry with the severity of skin involvement as measured by MRSS. They studied 74 patients through a retrospective chart review and patients were divided into three groups: normal motility ( $n=19)$, absent contractility $(n=40)$, and ineffective esophageal motility $(n=15)$. In $52 / 74(70 \%)$ patients that had a record of MRSS, the severity and extent of skin involvement as measured by MRSS did not differ in the three groups in unadjusted analysis $(p=0.19)$. In addition, upon dividing their patients into limited SSc and diffuse SSc, there was no difference in the proportions of normal esophageal motility, absent contractility, and ineffective esophageal motility among SSc subtypes ( $p=0.34$ ) (32). Unlike Kimmel et al., we did not categorize our patients into separate groups with different motility patterns. Rather, we carried out a direct correlation between the mean MRSS of each patient with the four parameters of esophageal manometry.

There are contradictory reports about the correlation between the severity of esophageal motor abnormalities and extent of skin involvement in SSc. Some studies have shown that patients with diffuse skin involvement have more severe and more frequent esophageal motor involvement, whereas other researchers have obtained conflicting results. Koshino et al. studied 52 patients diagnosed with SSc. The patients were divided into mild, moderate, and severe on the basis of a clinical scoring system having six parameters (five of which were related to mucocutaneous system): sclerodactyly, digital pitted scars, pigmentation of the body, digital contractures, short sublingual frenulum, and bibasilar pulmonary fibrosis. The severity was considered mild (score 1-2), moderate (score 3-4), or severe (score 5-6). They concluded that LESP decreased significantly as the grade of severity of SSc increased (33). Bassotti et al. used the Krieg and Meurer criteria to divide 125 patients with scleroderma into four groups; namely, type I (involvement of the fingers and hands, to the wrist), type II L (limited: proximal ascending sclerosis, including the forearm), type II D (diffuse: acral onset, with progressive diffuse evolution), and type III (primitive truncal onset with subsequent extension and early visceral involvement). Manometric abnormalities were seen in $80 \%$ of the patients and $\mathrm{pH}$-metric abnormalities were documented in $78 \%$ of the patients. They concluded that esophageal manometric abnormalities correlated significantly with the severity of the disease. However, abnormalities in esophageal pH-metry did not correlate. Similarly, those patients with more severe disease (types II L, II D, and III) had a significantly ( $p<$ o.001) lower LESP compared with those with less severe disease (type I) (34). Roman et al. studied high-resolution manometry in 49 patients with SSc. They found esophageal body dysmotility in 
all 14 patients with diffuse skin involvement and in 19/35 (54\%) with limited skin involvement. They concluded that esophageal dysmotility was more prevalent in diffuse SSc (35). Thus the above studies support the hypothesis that diffuse skin involvement is a predictor for more severe esophageal involvement in SSc.

However, there are also several studies that have not yielded any significant correlation between the severity of skin involvement and esophageal motor abnormalities in SSc. Airo et al. performed a retrospective study on 181 patients that were classified into four groups according to Le Roy and Medsger's 2001 criteria and the 1980 ARA criteria. They found that the severity of esophageal manometric abnormalities was not statistically significantly higher in patients with diffuse SSc, who have greater skin involvement than those with limited cutaneous involvement (27). Marie et al. failed to show any statistically significant difference between SSc subtypes (limited SSc vs. diffuse SSc) and the degree of esophageal manometric dysfunction in 43 patients with SSc (36). Lahcene et al. studied clinical, endoscopic, and manometric features of 194 consecutive patients with SSc. They found that esophageal motor disorders were common in both forms (limited SSc and diffuse SSc) of the disease, regardless of the degree of skin involvement. They concluded that the extent of skin involvement did not significantly influence the frequency or severity of manometric disorders (26). Savarino et al. studied 99 patients with SSc and found that LESP and wave amplitude were statistically similar in limited and diffuse subsets of SSc and lower than that of healthy controls (28). Crowell et al. performed a prospective study of 200 patients with SSc and 102 controls and studied their esophageal motor abnormalities. Classical scleroderma esophagus (reduced LESP with absent contractility) was observed

\section{References}

1. Arif T, Adil M, Hassan I. Antibody profile in systemic sclerosis patients: a crosssectional study from Kashmir Valley of India. J Pak Assoc Dermatol. 2018;28:4550 .

2. Varga J, Abraham D. Systemic sclerosis: a prototypic multisystem fibrotic disorder. J Clin Invest. 2007;117:557-67.

3. Krieg T, Takehara K. Skin disease: a cardinal feature of systemic sclerosis. Rheumatology (Oxford). 2009;48:iii1-iii18.

4. Domsic R, Fasanella K, Bielefeldt K. Gastrointestinal manifestations of systemic sclerosis. Dig Dis Sci. 2008;53:1163-74.

5. Arif T, Masood Q, Singh J, Hassan I. Assessment of esophageal involvement in systemic sclerosis and morphea (localized scleroderma) by clinical, endoscopic, manometric and $\mathrm{pH}$ metric features: a prospective comparative hospital based study. BMC Gastroenterol. 2015;15:24.

6. Calderaro DC, de Carvalho MAP, Moretzsohn LD. Esophageal manometry in 28 systemic sclerosis Brazilian patients: findings and correlations. Dis Esophagus. 2009;22:700-4.

7. Fox MR, Bredenoord AJ. Oesophageal high-resolution manometry: moving from research into clinical practice. Gut. 2008;57:405-23.

8. Tang DM, Pathikonda M, Harrison M, Fisher RS, Friedenberg FK, Parkman HP. Symptoms and esophageal motility based on phenotypic findings of scleroderma. Dis Esophagus. 2013;26:197-203.

9. Ntoumazios SK, Voulgari PV, Potsis K, Koutis E, Tsifetaki N, Assimakopoulos DA. Esophageal involvement in scleroderma: gastroesophageal reflux, the common problem. Semin Arthritis Rheum. 2006;36:173-81.

10. Subcommittee for Scleroderma Criteria of the American Rheumatism Association Diagnostic and Therapeutic Criteria Committee. Preliminary criteria for the classification of systemic sclerosis (scleroderma). Arthritis Rheum. 1980;23:58-90.

11. Le Roy EC, Black C, Fleischmajer R. Scleroderma (systemic sclerosis): classification, subsets and pathogenesis. J Rheumatol. 1988;15:202-5.

12. Benjamin SB, Richter JE, Cordova CM, Knuff TE, Castell DO. Prospective manometric evaluation with pharmacologic provocation of patients with suspected esophageal motility dysfunction. Gastroenterology. 1983;84:893-901. in 34\% patients with diffuse SSc and 32\% with limited SSc. They concluded that there is no difference between esophageal motor dysmotility and the subsets of the disease (37).

Our study is the first to make a direct correlation between objective measures of the severity of skin involvement (by MRSS) and values of esophageal manometric abnormalities in SSc without categorizing patients into different groups (such as hypoperistalis, aperistalsis, and normal peristalsis). However, our study has certain limitations, one of which is the small sample size. The mean duration of disease seen in our patients was considerably longer than that seen in most rheumatology clinics. Further, highresolution manometry and 24-hour $\mathrm{pH}$ monitoring were not performed in the study due to limitation of resources, which would have yielded important information about reflux. Since our aim was to determine a correlation between skin and esophageal involvement measured by MRSS and manometry, respectively, data regarding symptoms of gastroesophageal reflux or endoscopic findings were not included in this study.

\section{Conclusion}

Our study found that there is no statistical correlation between the extent of skin involvement as measured by MRSS and the severity of esophageal manometric abnormalities in patients with SSc. We also found that there is no difference between the manometric findings seen in limited and diffuse subsets of patients with the disease. Thus we believe that all patients with SSc should undergo esophageal manometry irrespective of the extent of skin involvement or the subtype of disease (limited or diffuse) they may be suffering from.
13. Chifflot H, Fautrel B, Sordet C, Chatelus E, Sibilia J. Incidence and prevalence of systemic sclerosis: a systematic literature review. Semin Arthritis Rheum. 2008;37:223-35.

14. Barnes J, Mayes M. Epidemiology of systemic sclerosis: incidence, prevalence, survival, risk factors, malignancy and environmental triggers. Curr Opin Rheumatol. 2012;24:165-70.

15. Manno RL, Wigley FM, Gelber AC, Hummers LK. Late age onset systemic sclerosis. J Rheumatol. 2011;38:1317-25.

16. Steen V, Domsic RT, Lucas M, Fertig N, Medsger TA. A clinical and serologic comparison of African American and Caucasian patients with systemic sclerosis. Arthritis Rheum. 2012;64:2986-94.

17. Hügle T, Schuetz P, Daikeler T, Tyndall A, Matucci-Cerinic M, Walker UA, et al. Late-onset systemic sclerosis-a systematic survey of the EULAR scleroderma trials and research group database. Rheumatology (Oxford). 2011;50:161-5.

18. Sharma VK, Trilokraj T, Khaitan BK, Krishna SM. Profile of systemic sclerosis in a tertiary care center in North India. Indian J Dermatol Venereol Leprol. 2006;72:416-20.

19. Hunzelmann N, Genth E, Krieg T, Lehmacher W, Melchers I, Meurer M, et al. The registry of the German Network for Systemic Scleroderma: frequency of disease subsets and patterns of organ involvement. Rheumatology (Oxford). 2008;47:1185-92.

20. Walker UA, Tyndall A, Czirják L, Denton C, Farge-Bancel D, Kowal-Bielecka O, et al. Clinical risk assessment of organ manifestations in systemic sclerosis: a report from the EULAR Scleroderma Trials and Research group database. Ann Rheum Dis. 2007;66:754-63.

21. Amjadi S, Maranian P, Furst DE, Clements PJ, Wong WK, Postlethwaite AE, et al. Course of the modified Rodnan skin thickness score in systemic sclerosis clinical trials: analysis of three large multicenter, double-blind, randomized controlled trials. Arthritis Rheum. 2009;60:2490-8.

22. Hinchcliff M, Huang CC, Wood TA, Mahoney JW, Martyanov V, Bhattacharyya S, et al. Molecular signatures in skin associated with clinical improvement during mycophenolate treatment in systemic sclerosis. J Inv Dermatol. 2013;133:197989. 
23. Ntoumazios SK, Voulgari PV, Potsis K, Koutis E, Tsifetaki N, Assimakopoulos DA. Esophageal involvement in scleroderma: gastroesophageal reflux, the common problem. Semin Arthritis Rheum. 2006;36:173-81.

24. Carlson DA, Hinchcliff M, Pandolfino JE. Advances in the evaluation and management of oesophageal disease of systemic sclerosis. Curr Rheumatol Rep. 2015;17:475.

25. Roberts CGP, Hummers LK, Ravich WJ, Wingley FM, Hutchins GM. A case control study of the pathology of oesophageal disease in systemic sclerosis (scleroderma). Gut. 2006;55:1697-703.

26. Lahcene M, Oumnia N, Matougui N, Boudjella M, Tebaibia A, Touchene B. Esophageal involvement in scleroderma: clinical, endoscopic, and manometric features. ISRN Rheumatol. 2011;2011:1-5.

27. Airo P, Case DD, Danieli E, Missale G, Cattaneo R, Cestari R. Oesophageal manometry in early and definite systemic sclerosis. Clin Rheumatol. 2005;24:370-6.

28. Savarino E, Mei F, Parodi A, Ghiro M, Furnari M, Gentile A, et al. Gastrointestinal motility disorder assessment in systemic sclerosis. Rheumatology (Oxford). 2013;52:1095-100.

29. Butt S, Emmanuel A. Systemic sclerosis and the gut. Expert Rev Gastroenterol Hepatol. 2013;7:331-9.

30. Gabrielli A, Avvenimento EV, Krieg T. Scleroderma. N Eng J Med. 2009;360:19892003.
31. Hachulla E, Launay D. Diagnosis and classification of systemic sclerosis. Clin Rev Allergy Immunol. 2011;40:78-83.

32. Kimmel JN, Carlson DA, Hinchcliff M, Carns MA, Aren KA, Lee J, et al. The association between systemic sclerosis disease manifestations and esophageal highresolution manometry parameters. Neurogastroenterol Motil. 2016;28:1157-65.

33. Koshino Y, Takai T, Kato T, Moriwaki H, Muto Y, Shikano Y, et al. Manometric evaluation of esophageal function in progressive systemic sclerosis with special regard to the disease severity. Gastroenterol Jpn. 1991;26:575-81.

34. Bassotti G, Battaglia E, Debernardi V, Germani U, Quiriconi F, Dughera L, et al. Esophageal dysfunction in scleroderma: relationship with disease subsets. Arthritis Rheum. 1997;40:2252-9.

35. Roman S, Hot A, Fabien N, Cordier JF, Miossec P, Ninet J, et al. Esophageal dysmotility associated with systemic sclerosis: a high-resolution manometry study. Dis Esophagus. 2011;24:299-304.

36. Marie I, Dominique S, Levesque H, Ducrotté P, Denis P, Hellot MF, et al. Esophageal involvement and pulmonary manifestations in systemic sclerosis. Arthritis Rheum. 2001;45:346-54.

37. Crowell MD, Umar SB, Griffing WL, DiBaise JK, Lacy BE, Vela MF. Esophageal motor abnormalities in patients with scleroderma: heterogeneity, risk factors, and effects on quality of life. Clin Gastroenterol Hepatol. 2017;15:207-13. 